\title{
T. БATYI
}

\section{СОКРАЩЕНИЕ ЧИСЛА ПЕРВИЧНЫХ ТЕРМИНОВ ФОНОЛОГИИ}

\author{
(Резюме)
}

Формализированная система теоретической фонологии представленная в моей книге [1] основывается на трёх специфически фонетических первичных терминах а также на пятнадцати характеризирующих их аксиомах Al-A15. Первичными терминами являются: I (класс всех идиолектов), $\mathbf{K}$ (класс всех видов фонетических свойств) и $\mathbf{O}$ (класс всех пауз).

В настоящей заметке показывается, что вследствие некоторого незначительного видоизменения рассматриваемой системы термин $\mathbf{O}$ можно определить с помошью остальных первичных терминов. Упомянутое видоизменение состоит в присоединении следуюшей простой аксиомы:

A16.

$$
u \in \bigcup \mathbf{I} \wedge x, y \in \mathbf{O} \cap \mathbf{P}{ }^{\prime} u \rightarrow \sim x \mathbf{T}_{i} y
$$

Показывается также, что после упомянутого видоизменения систему аксиом Al-Al6 можно несколько упростить. Именно, вводя символ $\mathbf{O}$ посредством соответствующего определения, можно опустить аксиомы А4, A11 и А16, так как они выводимы тогда из остальных аксиом.

Стоит добавить, что присоединение аксиомы А16 совсем несущественно с интуитивно-лингвистической точки зрения. 